\title{
Comparison of ultrasound-guided puncture drainage and incision drainage for deep neck abscess
}

\author{
Xuejie Fan $^{1,2,3,4}$, Shudong Tao ${ }^{1,2,3,4}$ \\ ${ }^{1}$ Department of Otorhinolaryngology Head and Neck Surgery, The Third Central Hospital of Tianjin, Tianjin, China; ${ }^{2}$ Tianjin Key Laboratory of \\ Extracorporeal Life Support for Critical Diseases, Tianjin, China; ${ }^{3}$ Artificial Cell Engineering Technology Research Center, Tianjin, China; ${ }^{4}$ Tianjin \\ Institute of Hepatobiliary Disease, Tianjin, China \\ Contributions: (I) Conception and design: X Fan; (II) Administrative support: X Fan; (III) Provision of study materials or patients: X Fan; (IV) \\ Collection and assembly of data: X Fan; (V) Data analysis and interpretation: X Fan; (VI) Manuscript writing: All authors; (VII) Final approval of \\ manuscript: All authors. \\ Correspondence to: Xuejie Fan. The Third Central Hospital of Tianjin, 83 Jintang Road, Hedong District, Tianjin 300170, China. \\ Email: 13652107195@163.com.
}

Background Deep neck space abscess is a common disease in otolaryngology-head, and neck surgery emergencies that result in significant morbidity with potential mortality. Traditional incision drainage with antibiotics is widely accepted worldwide. Recent studies have shown that ultrasound-guided drainage is an effective strategy and is less invasive for patients. The present study aimed to explore the difference between puncture and drainage guided by B-ultrasound and traditional surgical incision in treating deep neck space abscess.

Methods: A total of 60 patients with deep neck abscess were enrolled in the present study; 43 were distributed to the B-ultrasound puncture drainage group and 17 to the incision drainage group. Clinical data were collected, and differences between the 2 treatment options were compared.

Results: There were no differences in patients' systemic illness, age, and clinical features (diameter of an abscess, amount of drainage in first 3 days, and body temperature). The cure rate of both groups was $100 \%$; the number of hospitalization days of the B-ultrasound-guided puncture group (8 days) was significantly less than that of the incision drainage group (10.8 days).

Conclusions: Puncture drainage of neck abscess guided by B-ultrasound is a safe and effective treatment method and can reduce the patient's hospital stay.

Keywords: B-ultrasound guidance; neck abscess; puncture; incision

Submitted Jan 24, 2021. Accepted for publication Mar 29, 2021.

doi: $10.21037 /$ gs-21-120

View this article at: http://dx.doi.org/10.21037/gs-21-120

\section{Introduction}

The neck structure is complex, with most soft tissues and gaps extending in all directions, including airways, important blood vessels, and nerves. Deep neck abscesses are often caused by odontogenic and pharyngeal infections. Upper gastrointestinal infections and foreign bodies, cervical lymphadenitis, neck fistulas and cyst infections are also common causes of deep neck space infections. The currently accepted method for diagnosing abscesses is enhanced CT of the neck. Once the abscess formation is confirmed, the treatment principle is to completely drain the abscess. Improper control of deep neck infections can result in badly dangerous outcomes. Vascular rupture, mediastinal infection, empyema, sepsis, dyspnea, and renal liver failure are common complications when neck-deep

\footnotetext{
$\wedge$ ORCID: 0000-0002-7337-9125.
} 
abscesses could not be controlled. These complications could be life-threatening in severe cases. Therefore, neck infections, especially deep neck abscess formation, are of priority in clinical settings. A deep neck abscess is an infection of the fascia and space of the neck. It often occurs in the parapharyngeal space, submandibular space, masseter space, retropharyngeal space, sublingual space, prevertebral space, and carotid space (1). The most cause of an abscess is dental infection. Incision drainage combined with antibiotics is the main treatment method for abscesses (2). Incision drainage is effective but has several drawbacks. First, it can result in damage to important blood vessels and nerves. When the abscess is deep, surgical trauma danger is increased because the inflammatory tissue is easy to bleed, or the structure is not clear during the operation. Second, surgical trauma stress can easily lead to complications when patients who suffer from the operation will be more sensitive to pathogenic bacteria in the environment and more likely to get sick. Third, open incisions may cause tumor dissemination when the abscess is caused by a tumor $(2,3)$. Finally, incision scars can also cause aesthetic defects. Therefore, carefully opening the abscess cavity, avoiding tissue damage, and protecting important tissue structures are important.

Several studies have shown that puncture drainage guided by $\mathrm{B}$-ultrasound is a more effective option than incision drainage for some deep neck abscesses. Puncture drainage can avoid the above disadvantages of incision drainage. It reduces the difficulty of the operation and avoids the trauma caused by the operation to the patient. If the abscess is caused by a tumor, it also avoids the spread of the tumor, and finally there is no surgical scar. An earlier study showed that 5 patients were successfully treated for deep neck abscesses by puncture drainage (4). Yeow et al. also showed a case of deep neck abscesses in the parotid gland and retropharyngeal space $(5,6)$. Al-Belasy and Gudi et al. reported cases of puncture drainage in the masseter space $(7,8)$. For the submandibular space, parapharyngeal space, and peritonsillar space, B-guided puncture drainage has also been shown to be an effective option (9-12). However, most of these studies were case reports, or the number of cases was small.

The present study was observational. Sixty cases in our department that met the criteria were enrolled and divided into the B-guided puncture drainage and incision drainage groups. Clinical data and treatment effects were analyzed.

We present the following article in accordance with the STROBE reporting checklist (available at http://dx.doi. org/10.21037/gs-21-120).

\section{Methods}

\section{Patients}

Patients diagnosed (from January 2015 to December 2019) with neck abscesses were enrolled in the study. All enrolled patients supplied signed informed consent. All procedures performed in this study involving human participants were in accordance with the Declaration of Helsinki (as revised in 2013). The ethics committee approved the present study of Tianjin's Third Central Hospital (No. IRB2020056-01). The inclusion criterion was abscesses in the deep neck space, as shown by computed tomography (CT), B-ultrasound, or magnetic resonance imaging (MRI). Abscesses were not widespread or in multiple locations. Exclusion criteria were as follows: (I) secondary neck abscess caused by space-occupying lesions, trauma, or surgery; (II) patients who did not provide signed informed consent; (III) those with autoimmune disease and coagulopathy; (IV) scattered abscesses (i.e., >2 areas with abscesses); and (v) those with necrotizing fasciitis.

\section{Treatment methods}

Routine examinations were done after admission to the hospital; B-ultrasound, often in conjunction with CT or MRI, was used to determine the extent of inflammation and abscess formation. Patients were then treated with puncture or incision drainage and intravenous antibiotic therapy.

\section{Puncture drainage method}

The patient was placed in the supine position. B-ultrasound was performed to evaluate the location, size, and adjacent tissues of the abscess. Important issues that could be affected during punctures, such as parotid gland, submandibular gland, internal carotid artery, internal jugular vein, neck carotid artery, and facial nerve, were noted. Routine disinfection, draping, 2\% lidocaine for local anesthesia were performed for the patient before operating. Under B-ultrasound monitoring, puncture drainage was performed. B-ultrasound was performed regularly to monitor the size of the abscess.

\section{Incision drainage method}

The incision was made from swelling of the neck to the 
low position of the abscess cavity. Subcutaneous tissue was separated until it reached the abscess cavity. Pus was extracted with a sterile needle tube for bacterial culture. Necrotic tissue in the abscess cavity was cleaned up, and a suction device absorbed pus. The abscess cavity was flushed repeatedly with normal saline, metronidazole, hydrogen peroxide, or diluted iodophor solution. One end of the drainage tube is placed in the abscess cavity, and the other end relates to a negative pressure drainage ball.

\section{Patient characteristics}

Patient characteristics were collected, including age, sex, systemic illness, the largest diameter of the abscess, highest temperature, location of the abscess, duration of a retention drainage tube in an abscess (indwelling time for short in the article), average drainage volume of the first three days after drainage, retreatment of multiple punctures or incisions, cure rate, complications, tracheotomy, and the number of hospitalization days.

\section{Complications and standard of cure}

Complication criteria were bleeding, exudation, airway injury, gland injury, nerve injury, vascular injury, decoupling, other puncture complications, sepsis, mediastinal infection, pericarditis, and jugular vein thrombosis, pneumonia, arterial infection, dyspnea, and other infectious complications. The cure criteria included the abscess cavity shrinking naturally and having drainage of pus within $24 \mathrm{~h}<1 \mathrm{~mL}$. No new abscesses, local pain, and abnormal body temperature were observed after removing the drainage tube. There were no recurrences within 2 weeks after discharge and at the 6-month telephone follow-up.

\section{Statistical analysis}

The R software ggpubr (version 0.4.0) (https://github.com/ cran/ggpubr) and ggstatsplot (version 0.5.0) (https://cran. r-project.org/web/packages/ggstatsplot/index.html) were used for the statistical analysis. Wilcoxon test was used to compare the mean value of 2 groups.

\section{Results}

A total of 60 cases met the inclusion criteria; 43 cases were distributed to the puncture drainage group and 17 cases to the incision drainage group. The cure rate of the puncture group and the incision group is $100 \%$. There were no statistical differences between the 2 groups on demographic characteristics, systemic diseases, and abscess characteristics (Figure 1). The most common abscess location in the puncture group was in the parapharyngeal space and submandibular space. The most common abscess location in the incision group was in the submandibular space, parapharyngeal space, and posterior pharyngeal space (Figure 2). There were no significant differences in terms of location between the groups. One patient in the incision group had pneumonia. There were 2 cases of multiple punctures in the puncture group and 0 cases in the incision group. There was 1 case of tracheotomy in each of the groups (Table 1). Ultrasound results from two cases are shown (Figure 3). In case 1, the heterogeneous mass $\left(\sim 7 \times 6.6 \mathrm{~cm}^{2}\right)$ was found in the submandibular area's soft tissue on day 0 ; the mass had an irregular shape, unclear boundary, and partial fluidity. B-ultrasound-guided puncture and drainage of the submandibular space abscess were conducted immediately. On day 4 , the heterogeneous mass $\left(\sim 3.5 \times 1.6 \mathrm{~cm}^{2}\right)$ was found in the submandibular space's soft tissue, with a small amount of liquid area and drainage tube echo. On day 7 , the hypoechoic area $\left(\sim 3.1 \times 1.5 \mathrm{~cm}^{2}\right)$ was found in the submandibular space's soft tissue. The drainage tube echo was observed on the same day, and no obvious liquid dark area was found. In case 2, a mixed echo mass in the left parapharyngeal space was observed on day 0 ; the mass had an unclear boundary and irregular shape. Abscess formation in the parapharyngeal space was suspected; therefore, B-ultrasound-guided puncture and drainage of the parapharyngeal space abscess were conducted immediately. Upon re-examination on day 6, the abscess was found to have a liquid dark area about $2.4 \times$ $0.5 \mathrm{~cm}^{2}$, with striped echo and scattered enhanced bright spots. The echo of the drainage tube was observed inside. On day 9, the left anterior cervical space showed a mixed echo area of about $1.9 \times 0.1 \mathrm{~cm}^{2}$, with a clear boundary and scattered enhanced bright spots (Figure 3).

The drainage tube's average indwelling time in the puncture group was 6.9 days compared with 10.6 days in the incision group (Figure 4). The average length of hospital stay in the puncture group was significantly shorter than that of the incision group ( $8 v s .10 .8, \mathrm{P}=0.00028)$.

\section{Discussion}

Deep neck space infections can cause serious complications. Several studies have shown that the risk of mortality is 
A

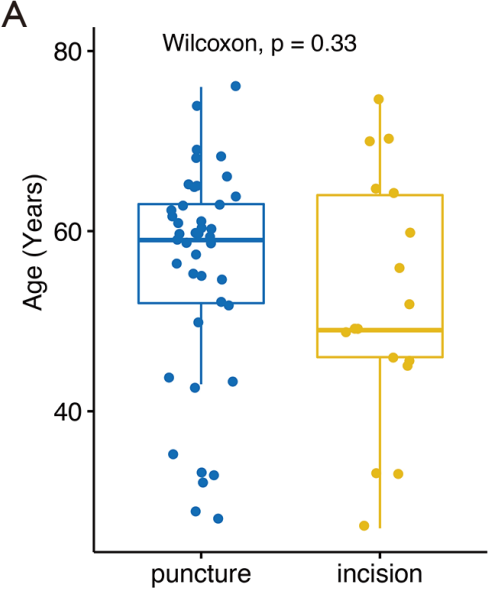

C

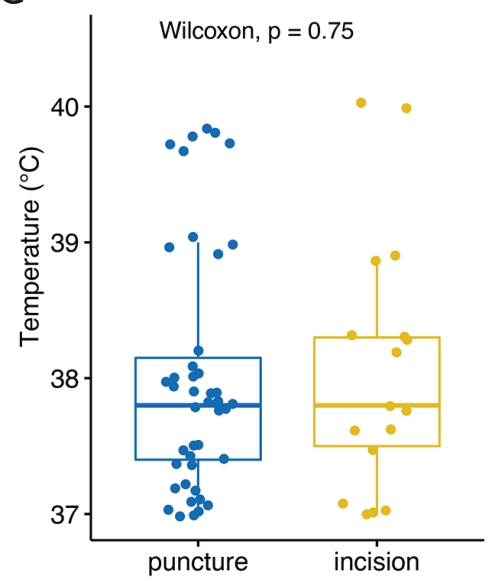

B

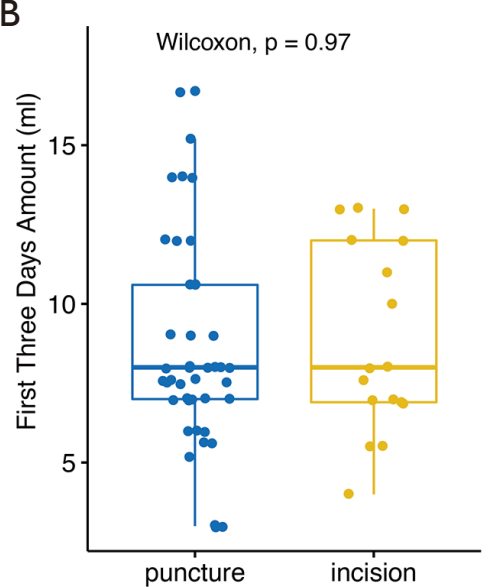

D

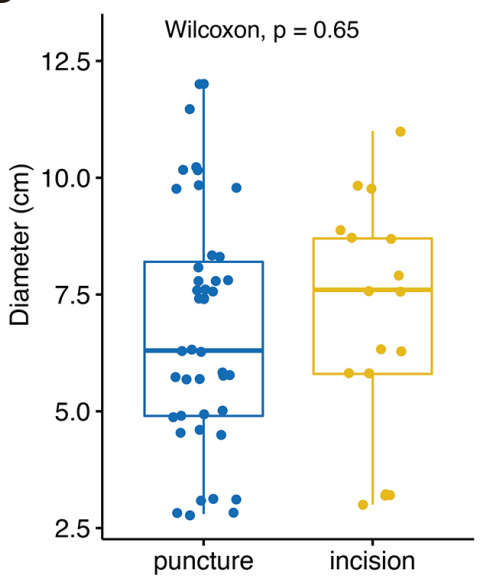

Figure 1 Statistical information of enrolled patients. (A) Age of patients in the puncture and incision groups; (B) drainage amount in average drainage volume of the first 3 days after drainage $(\mathrm{mL})$ in the puncture and incision groups; $(\mathrm{C})$ the temperature of patients in the puncture and incision groups; (D) abscess diameter in the puncture and incision groups.

significantly increased once a patient develops complications, such as mediastinitis, pericarditis, airway injury, jugular vein thrombosis, pneumonia, and arterial injury. An abscess often takes 3-5 days to form following a neck infection. Therefore, the early detection of abscesses and thorough drainage is crucial.

Puncture drainage was first used to puncture and drain abscesses in the abdominal cavity and parenchymal organs, such as liver abscesses, peri-appendicular abscesses, intestinal space abscesses, etc. The development in these fields is also relatively rapid. As the puncture drainage technology matures, gradually applied to the drainage of abscesses in the maxillofacial and deep neck spaces. Compared with other inspection methods, like CT, B-ultrasound has advantages for soft tissue inspection. B-guided puncture and drainage have been widely used in other parts of the body (13-16). The advantage of this treatment method is that the drainage tube can be inserted under the real-time guidance of $\mathrm{B}$-ultrasound to reach the required location and drain the abscess thoroughly. The distance between the puncture needle and the arterial sheath or important organs can be checked in real-time, eliminating the need for estimations or blind puncture. Also, abscess development is a dynamic process, and exact puncture timing, dynamic observation after drainage, and insufficient drainage monitoring can be completed under B-ultrasound's assistance.

To carry out deep neck abscess puncture and drainage under the guidance of B-ultrasound, it is necessary to have good B-ultrasound equipment, puncture equipment, etc. However, the most important thing is the requirement of 
A

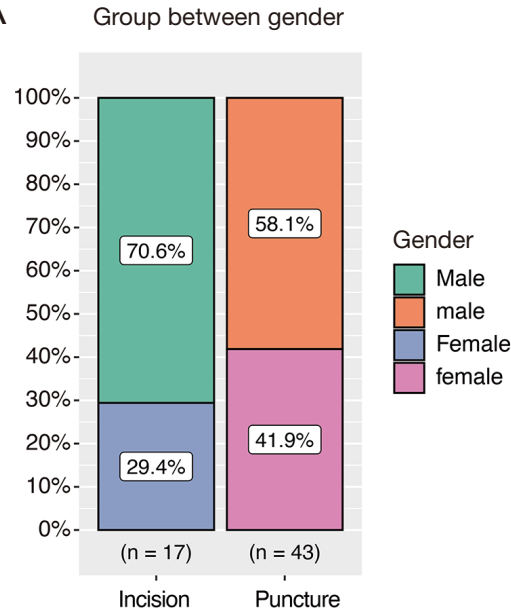

B

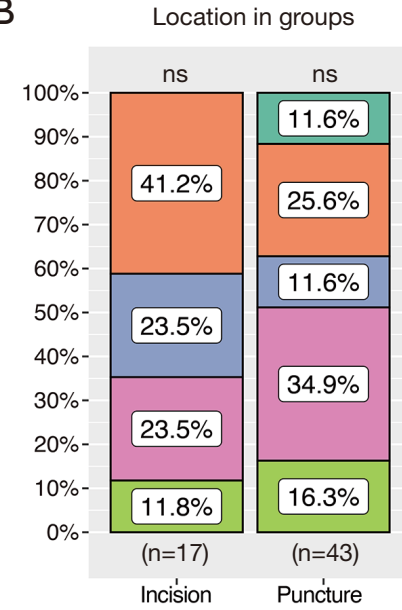

Location

$\square$ submandibular space/

parapharynbgeal space submandibular space

retropharyngeal space

parapharynbgeal space

masticator space

ns: no significant effect

Figure 2 Distribution of gender and abscess position between the two groups. (A) Comparison of sex between the puncture and incision groups; (B) comparison of abscess location between the puncture and incision groups.

Table 1 Clinical characteristics for all enrolled patients

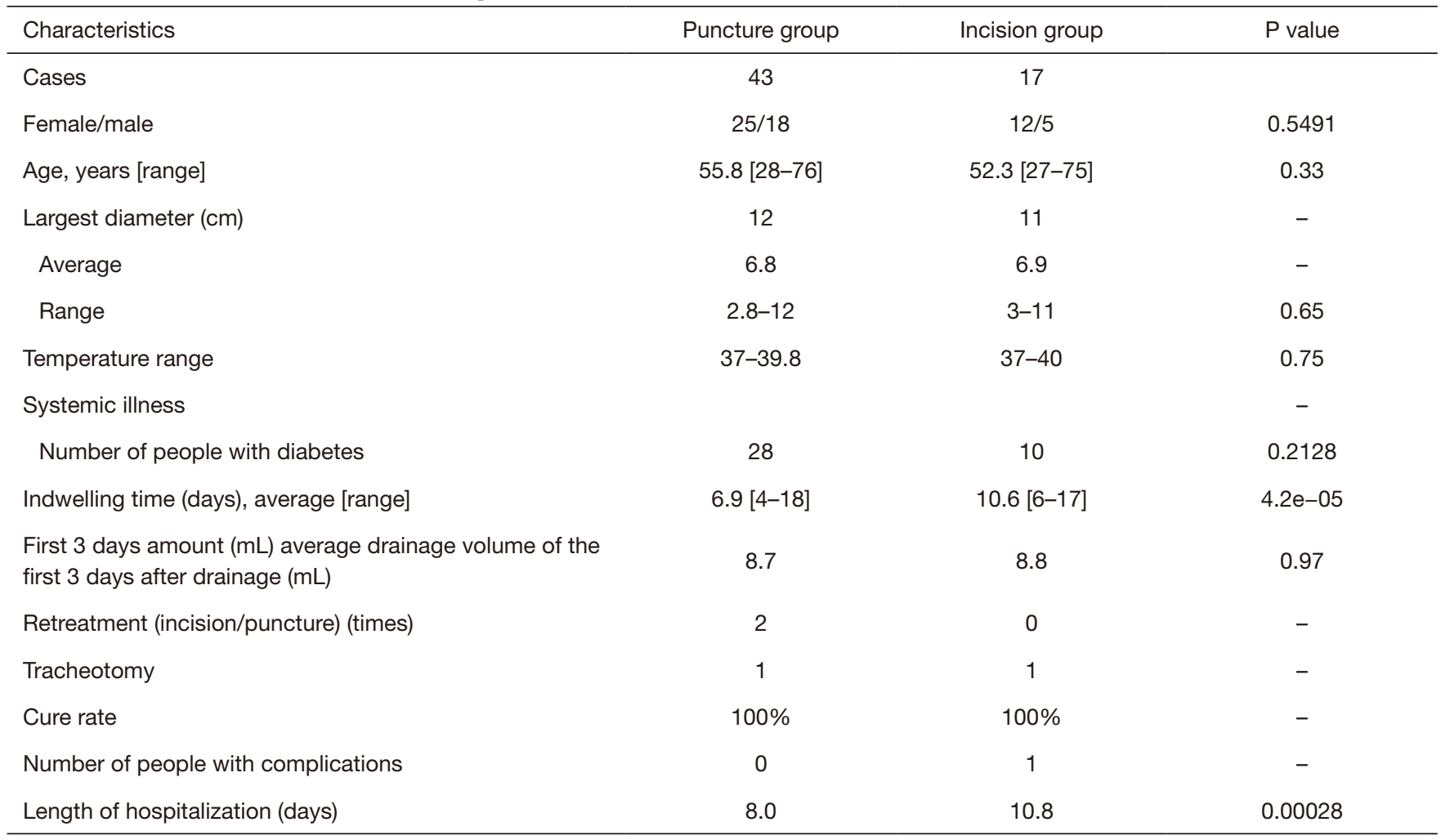

the operator, which requires the operator to have a clear understanding of the structure of the neck and have a good understanding of the B-ultrasound image. Accurate identification and skilled operation methods.

How to safely and accurately perform ultrasound- guided puncture drainage? There are several methods and precautions for puncture drainage under the guidance of B-ultrasound. One is best puncture timing. Puncture and drainage should be performed only after an obvious abscess wall has been formed. There may be only some 


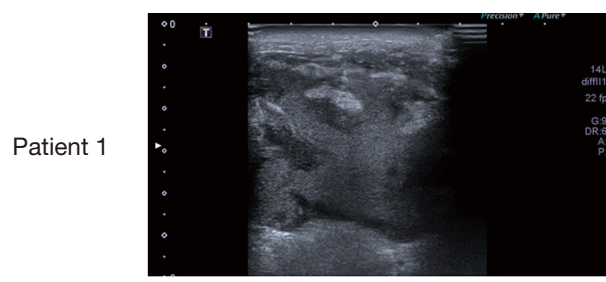

Day $0: 7.0 * 6.6 \mathrm{~cm}$

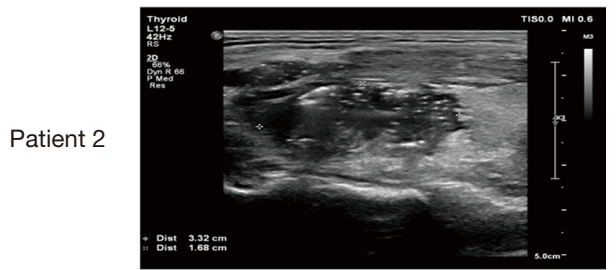

Day $0: 3.8 \times 1.7 \mathrm{~cm}$

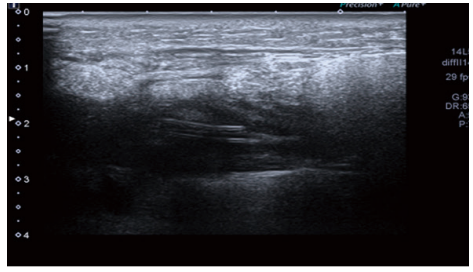

Day $4: 3.5^{\star} 1.6 \mathrm{~cm}$

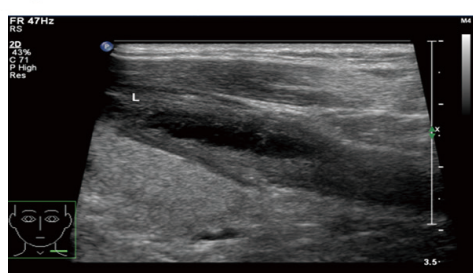

Day 6: $2.4 \times 0.5 \mathrm{~cm}$

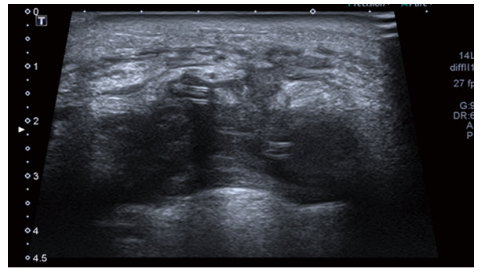

Day $7: 3.4^{\star} 1.5 \mathrm{~cm}$

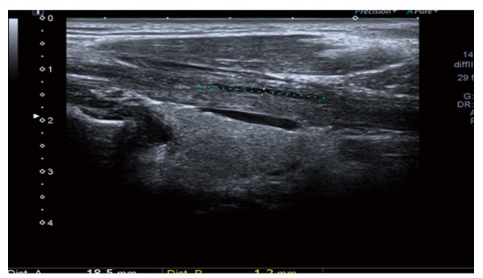

Day $9: 1.9 \times 0.1 \mathrm{~cm}$

Figure 3 B-ultrasonic of 2 puncture drainage cases. Days and diameters are shown.

A

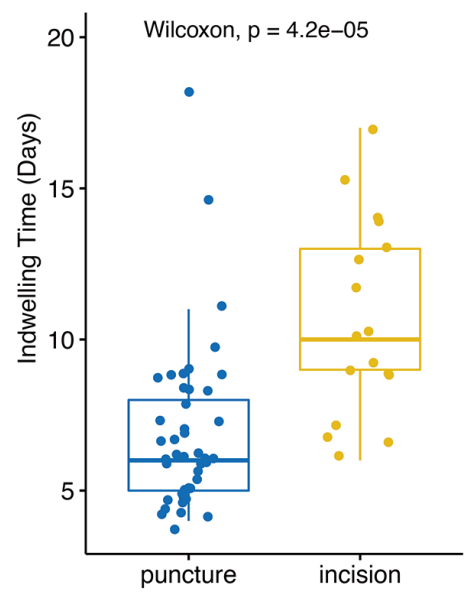

B

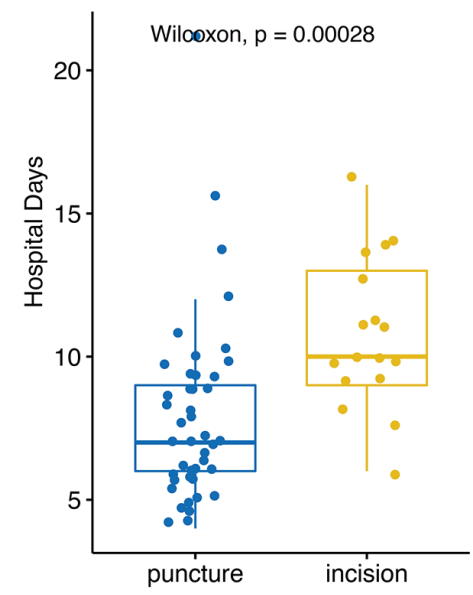

Figure 4 Distribution of drainage tube retention time and hospitalization days between the two groups. (A) A comparison of the number of days of drainage tube retention between the puncture and incision groups; (B) comparing the number of days of hospitalization between the puncture and incision groups.

extensive inflammatory reaction in the early stage of abscess formation that is not suitable for puncture drainage treatment. The second is to determine the precise route of the puncture needle. Avoiding important blood vessels, nerves, and glands is crucial for puncturing. Because we use fine needle puncture, it generally does not cause nerve severance damage. If the puncture needle happens to penetrate the nerve, then adjust the position of the puncture needle as soon as possible, generally, it will not cause permanent damage. The third is the precise depth of needle insertion. The needle tip should be in the center of the liquefaction zone, and the force of insertion should be moderate. It is necessary to observe whether the drainage is smooth after the puncture. If the drainage volume does not match the abscess cavity observed by B-ultrasound, it means that there is an abscess cavity that has not been drained. The position of the puncture drainage needs to be adjusted. It should be noted that the anatomical boundaries of the inflammatory and infected tissues are not clear, and it is needed especially carefully to identify when B-ultrasoundguided puncture; otherwise, there will be related injuries.

Zeng et al. found that there are some situations where puncture drainage cannot be used, including poor drainage caused by thick pus or narrow puncture port and lumen (17). 
However, we believe that the viscosity of pus is related to the timing of drainage. Abscess formation takes time. Pus is viscous when there is an incompletely liquefied tissue. Although it is difficult to drain, it becomes easier when abscess formation is completed. For poor drainage under B-ultrasound guidance, Lin et al. implemented a contradrainage method for head and neck abscess in 14 patients and successfully drained thick pus (18).

Biron et al. stated that all patients with airway obstruction should be treated with incision drainage (19). The indications for this graduate student's puncture drainage are more extensive; if the abscess is not widespread and frequent, puncture drainage can be performed. Case 1 was a good example of a deep neck abscess. The abscess was located around the submandibular. The patient had third-degree dyspnea and received a tracheotomy at once before being treated with a puncture drain. The prognosis was good, and the patient had no complications.

In their study, Biron et al. excluded older adults ( $>65$ years) (19). This contrasts with our study, where most patients were aged $>65$ years. Neck infections and abscess formation are common among the elderly and those with low immunity.

Our study showed that the length of hospital stay in the puncture drainage group was significantly shorter than that of the incision group. Shorter hospital stay results in reduced complications and costs. The secondary puncture drainage ratio was relatively low in our study (2/43 patients), which was consistent with Biron et al.'s study (19).

In the present study, patients with extensive abscesses and necrotizing fasciitis were not included, as such patients have a large amount of necrotic tissue. As there are many fibrous spaces between abscesses, puncture drainage alone cannot drain the abscess completely. Surgical incision and debridement are still needed. Although we think that the observation period of 6 months after this abscess treatment is basically enough, we have not observed the long-term adverse reactions after the abscess treatment. In future studies, we will extend the follow-up period to observe the long-term adverse effects reaction. In addition, the sample size of this study is relatively small. In future studies, we will expand the sample size to verify our study.

\section{Conclusions}

The present study's findings indicated that the number of days of hospitalization for puncture drainage guided by B-ultrasound was significantly shorter than that for incision drainage. Puncture drainage of neck abscess guided by B-ultrasound is a safe and effective treatment method and is useful in the clinical setting.

\section{Acknowledgments}

The authors thank the study participants for their willingness to cooperate with our study.

Funding: None.

\section{Footnote}

Reporting Checklist: The authors have completed the STROBE reporting checklist. Available at http://dx.doi. org/10.21037/gs-21-120

Data Sharing Statement: Available at http://dx.doi. org/10.21037/gs-21-120

Conflicts of Interest: Both authors have completed the ICMJE uniform disclosure form (available at http://dx.doi. org/10.21037/gs-21-120). The authors have no conflicts of interest to declare.

Ethical Statement: The authors are accountable for all aspects of the work in ensuring that questions related to the accuracy or integrity of any part of the work are appropriately investigated and resolved. This research comprised human participants and was approved by The Third Central Hospital of Tianjin (No. IRB2020-05601). Informed consent was obtained from all participants included in the study. All procedures performed in this study involving human participants were in accordance with the Declaration of Helsinki (as revised in 2013).

Open Access Statement: This is an Open Access article distributed in accordance with the Creative Commons Attribution-NonCommercial-NoDerivs 4.0 International License (CC BY-NC-ND 4.0), which permits the noncommercial replication and distribution of the article with the strict proviso that no changes or edits are made and the original work is properly cited (including links to both the formal publication through the relevant DOI and the license). See: https://creativecommons.org/licenses/by-nc-nd/4.0/.

\section{References}

1. Santos Gorjón P, Blanco Pérez P, Morales Martín AC, 
et al. Deep neck infection. Review of 286 cases. Acta Otorrinolaringol Esp 2012;63:31-41.

2. Vieira F, Allen SM, Stocks RM, et al. Deep neck infection. Otolaryngol Clin North Am 2008;41:459-83, vii.

3. Chang KP, Chen YL, Hao SP, et al. Ultrasound-guided closed drainage for abscesses of the head and neck. Otolaryngol Head Neck Surg 2005;132:119-24.

4. Baatenburg de Jong RJ, Rongen RJ, Laméris JS, et al. Ultrasound-guided percutaneous drainage of deep neck abscesses. Clin Otolaryngol Allied Sci 1990;15:159-66.

5. Yeow KM, Hao SP, Liao CT. US-guided percutaneous catheter drainage of parotid abscesses. J Vasc Interv Radiol 2000;11:473-6.

6. Yeow KM, Hao SP, Liao CT. US-guided percutaneous catheter drainage of a deep retropharyngeal abscess. J Vasc Interv Radiol 1999;10:1365-9.

7. Al-Belasy FA. Ultrasound-guided drainage of submasseteric space abscesses. J Oral Maxillofac Surg 2005;63:36-41.

8. Gudi SS, Sarvadnya J, Hallur N, et al. Ultrasound guided drainage of submasseteric space abscesses. Ann Maxillofac Surg 2013;3:31-4.

9. Boscolo-Rizzo P, Da Mosto MC. Submandibular space infection: a potentially lethal infection. Int J Infect Dis 2009; 13:327-33

10. Simard RD, Socransky S, Chenkin J. Transoral Point-ofCare Ultrasound in the Diagnosis of Parapharyngeal Space Abscess. J Emerg Med 2019;56:70-3.

11. Todsen T, Stage MG, Michaelsen SH, et al. Protocol for a randomised clinical trial of transoral ultrasound versus standard of care in the diagnosis of peritonsillar abscess. Dan Med J 2019;66:A5573.

12. Hagiwara Y, Araga T, Saito Y, et al. Utility of transoral

Cite this article as: Fan X, Tao S. Comparison of ultrasoundguided puncture drainage and incision drainage for deep neck abscess. Gland Surg 2021;10(4):1431-1438. doi: 10.21037/gs-21-120 pharyngeal ultrasonography for puncture drainage of peritonsillar abscess. Clin Case Rep 2019;7:839-40.

13. Manno M, Deiana S, Ottaviani L, et al. Endoscopic ultrasound-guided drainage of an abdominal abscess using a lumen-apposing metal stent. Endoscopy 2020;52:E2 19-20.

14. Matsubara S, Isayama H, Nakai $Y$, et al. Endoscopic ultrasound-guided gallbladder drainage with a combined internal and external drainage tubes for acute cholecystitis. J Gastroenterol Hepatol 2020;35:1821-7.

15. Surya M, Bhoil R, Sharma YP. Study of ultrasound-guided needle aspiration and catheter drainage in the management of liver abscesses. J Ultrasound 2020;23:553-62.

16. Wang $\mathrm{Y}$, Zhang J, Dong L, et al. Orbital abscess treated by ultrasound-guided fine needle aspiration and catheter drainage: A case report. Medicine (Baltimore) 2019;98:e17365.

17. Zeng DS, Chen JY, Yu D, et al. Application of Percutaneous Puncture in Maxillofacial and Cervical Space Infection with the Guide of B-mode Ultrasound. Journal of Medical Research 2019;48:121-124, 39.

18. Lin Y, An L, Li L. New treatment choice of head and neck cellulitis: multi-catheter drainage guided by ultrasound percutaneous puncture. Chinese Journal of Otorhinolaryngology Head and Neck Surgery 2017;52:110-2.

19. Biron VL, Kurien G, Dziegielewski P, et al. Surgical vs ultrasound-guided drainage of deep neck space abscesses: a randomized controlled trial: surgical vs ultrasound drainage. J Otolaryngol Head Neck Surg 2013;42:18.

(English Language Editor: R. Scott) 